\title{
Mediações culturais e da informação no contexto dos folguedos alagoanos
}

\author{
Mediaciones Culturales y de la Información en el contexto de los Folguedos Alagoanos
}

Cultural and nformation mediations in the context of Folguedos Alagoanos

Mona Cleide Quirino da Silva FARIAS, Maria de Loudes LIMA

Universidade Federal de Alagoas-UFAL, Maceió/AL/Brasil, monaquirino@gmail.com

\begin{abstract}
Resumen
Las mediaciones culturales y de la información versan sobre posibilidades de articular procesos interpretativos sobre la diversidad de expresiones culturales en contextos culturales distintos. En este estudio se abordan con estas metodologías los folguedos alagoanos, fiesta folclórica de Alagoas, en el nordeste de Brasil. Los folguedos representan y expresan, por medio de múltiples lenguajes, la cultura popular local.

Palabras clave: Mediación cultural. Mediación informacional. Folguedos Alagoanos. Brasil. Manifestaciones culturales. Semiótica.
\end{abstract}

\section{Introdução}

Entendemos que existem variadas formas de manifestações culturais por todo o mundo, cada qual com suas características e linguagens próprias. Logo, consideramos que as linguagens são como instrumentos mediadores articuladas pelos foguedos na relação com a comunidade. No contexto desse estudo os folguedos são entendidos como expressões que fornecem uma diversidade de elementos sígnicos, expressos nas mais variadas formas de linguagem, por exemplo (visual, verbal, oral e sonora).

As linguagens, são modos de expressão (Machado, 2003) e no contexto de qualquer manifestação artística e cultural auxiliam na comunicação da própria expressão, assim como no entendimento da cultura popular, em particular a do Estado de Alagoas - Nordeste do Brasil. Vale destacar que no Brasil podemos verificar uma diversidade linguística e cultural as quais influenciam e ainda são influenciadas pelas manifestações culturais. Desse modo, ententemos que em diversas regiões como no caso do Nordeste do Brasil há uma multiculturalidade de expressões que resultam no caráter híbrido das inúmeras expressões culturais.

Os folguedos são desse modo um elemento expressivo da cultura popular em Alagoas e por isso consideramos que há nestes uma diversida-

\begin{abstract}
The cultural and information mediations refer to the possibilities of articulating interpretative processes about a diversity of cultural expressions in different cultural contexts. In this study we highlight folguedos Alagoanos a folkloric festival of Alagoas- northest of Brazil). Folguedos represent and express, through multiple languages, the local popular culture.
\end{abstract}

Keywords: Cultural mediation. Information mediation. Folguedos Alagoanos. Brazil. Cultural manifestations. Semiotics.

de de informações as quais podem contribuir no entendimento do contexto histórico e cultural de Alagoas. Para tanto, objetivamos discutir sobre a necessidade de processos como da mediação cultural e da informação para a compreensão dos folguedos em Alagoas, ou ainda, de atividades culturais que envolvam esse tipo de manifestação cultural no intuito de refletir sobre a finalidade desses processos na perspectiva de uma representação da cultura popular via as manifestações culturais, os folguedos.

\section{Mediações culturais e da informação}

A informação é condição básica para o desenvolvimento dos indivíduos. Compreende-se que a informação é um elemento intangível, só podendo torna-se significativa a partir do instante em que é interpretada pelo usuário, possibilitando a transformação do seu acervo de conhecimento, na construção de novos conhecimentos. Desse modo, podemos dizer que a informação passa a existir no instante de uma apropriação, mesmo que não seja consciente, mas que agregue significados aos conhecimentos dos sujeitos (re)construindo novos conhecimentos.

Sobre a apropriação da informação, é sensato comentar quanto a mediação da informação. Almeida Júnior em sua pesquisa sobre La mediación de la información y la lectura informacional (2009) diz que a mediação da informação é: "Toda acto de interferencia - realizado por el 
profesional de la información [...]" independente que aconteça de forma direta e indireta, mas que de fato proporcione a apropriação da informação possibilitando a satisfação do sujeito, em vista da sua necessidade informacional.

Em consonância com essa definição expressa nas linhas anteriores é que se pensa a mediação da cultura, isto é, mediação cultural. Coelho Neto (2012, p. 268) diz que a mediação cultural são processos de diferentes naturezas cujo objetivo é promover a aproximação entre indivíduos, ou coletividades para com as obras de cultura e arte e tal aproximação tem por objetivo facilitar a compreensão das obras, isto é, propondo um conhecimento sensível e intelectual. Sobre esta última palavra, podemos propor uma ou várias reflexão(ões) sobre a mediação cultural. Será que todo conhecimento que podemos adquirir em torno da cultura e das artes é possível ser sensível e apenas intelectual? De certo que isso não será respondido nesse momento, mas fica aqui tal indagação.

Davallon (2007) diz que a mediação cultural a nível funcional visa em propor a interface entre o público e as obras de arte, na intenção de permitir a apropriação desse público com a arte de modo geral. Diante dessas colocações, compreende-se que a mediação cultural é um processo que visa promover o envolvimento dos sujeitos no universo da cultura possibilitando que estes sujeitos, atores, públicos das obras de cultura e arte, se apropriem, julguem, interpretem, tragam para sua realidade o que de fato foi compreendido, só dessa forma podemos pensar na construção de conhecimentos.

É relevante colocar que a mediação cultural pode acontecer por meio de diferentes níveis, no que corresponde as suas atividades, e esses caracterizam-se por modos de mediação cultural como, por exemplo, a ação cultural, a animação cultural e a fabricação cultural (Coelho $\mathrm{Ne}$ to, 2012, p. 268). Em meio a isso é preciso enfatizar sobre a participação de um profissional da informação, seja este caracterizado como mediador, agente cultural, ou até mesmo, mediador cultural. O profissional não é neutro e por isso não deve estar fechado para discussões de caráter cultural, pois é preciso o seu entendimento sobre cultura ou ao menos um posicionamento quanto aos fenômenos da cultura.

A cultura é entendida como condição humana na construção e transformação do conhecimento. Conforme Coelho Neto (1986), do mesmo modo que a educação está voltada para a constituição do indivíduo, assim também está a cultura. Nessas condições o processo de mediação torna-se significativo quando se propõe mediar a cultura, pensando na sua posterior interpretação e apropriação. Assim, é necessário atentar para o fato de que "O cultural constitui um campo multi e interdisciplinar" (Falcon, 2002, p. 80) o que proporciona aos sujeitos inúmeras interpretações sobre a realidade apresentada.

Sendo a informação elemento determinante na comunicação e diálogo entre os sujeitos assim como na relação entre as manifestações culturais e as comunidades, é necessário também entender os diversos contextos culturais na busca de um entendimento sobre os fenômenos multiculturais presentes, principalmente na comunicação das manifestações culturais. Vale destacar que com a mediação cultural e a mediação da informação, não devemos priorizar apenas um uso supérfluo de determinados suportes, nem mesmo o consumo, seria meramente fazer uso de algo e depois descartá-lo. No entanto é necessário conhecer para que haja a apropriação. Nessa perspectiva de informação, a apropriação condiz no ato de alterar, transformar e quem sabe poder agregar conhecimento (Almeida Júnior, 2007):

A apropriação da informação, que fique claro, pressupõe uma alteração, uma transformação, uma modificação do conhecimento, sendo assim uma ação de produção e não meramente de consumo.

A cultura é determinante na formação e desenvolvimento do indivíduo e coletivo, pois esta condiciona a visão de mundo dos homens e assim, como discorre Almeida Júnior (2009, p. 93) "A informação está imersa em ideologias[...]". Assim também podemos dizer que a cultura encontra-se na mesma condição, isto é, não está deslocada de interesses econômicos e políticos. Em suma, a cultura, não é somente determinante, ela também em alguns contextos é determinada. Logo, entendemos a mediação da cultura como parte da mediação da informação, quando compreende-se esta primeira como processo de aproximação do indivíduo e coletividade e as obras de arte, cujo objetivo é tornar possível a compreensão das práticas culturais, assim como seu conhecimento. Como apresenta Coelho Neto (2012), na busca de formar públicos para a cultura ou de iniciar os indivíduos na prática efetiva de uma determinada atividade cultural.

É imprescindível refletir sobre a mediação cultural, visto que estamos rodeados de signos culturais, necessitando desse modo, de interpretações e compreensão. Salientamos da importância não somente do profissional da informação nos processos de mediação citados, como também das funções dos espaços culturais, assim como dos espaços escolares, pois o diálogo, ou 
melhor, a comunicação como aqui compreendemos, tomando como base esta definição de Coelho Neto (2011) é um processo no qual há diversas linguagens e boa parte dessas linguagens possibilitam a comunicação como também a criação artística para o desenvolvimento do ser até seu processo de 'aprender a ser' .

Os espaços culturais como, por exemplo, os equipamentos culturais, os quais podem ser caracterizados por bibliotecas, museus, centros culturais, etc., em sua maioria não fazem valer suas funções em meio a sociedade, pois muitas vezes encontram-se deslocados das comunidade nas quais deveriam se fazer presentes, por se dizerem como espaços da cultura, isto é, do povo. No entanto, essa relação não concretizada por tais espaços acabam por impossibilitar, por exemplo, a participação do homem periférico nesses ambientes. É evidente que não podemos ser ingênuos a ponto de colocar a culpa nos edifícios, monumentos, onde estão alocados esses espaços, pois a questão é bem mais complexa, a de uma política cultural e digo mais, institucional, muitas vezes mal estabelecida, quando esta de fato existe.

As bibliotecas, museus e centros culturais são referências, de maneira geral, da cultura de um povo, por isso é preciso que reflitam suas atuações, funções, que de fato se efetivem. Assim, é possível pensar a mediação cultural e da informação como determinantes a esses espaços, buscando a interface e a relação comunidade/ informação/cultura. Com isso, é possível vislumbrar sujeitos envolvidos e conscientes de sua cultura, suas formas de manifestar-se, ainda, dos seus deveres e direitos enquanto cidadão.

As reflexões sobre mediação da cultura e da informação, assim como a compreensão sobre apropriação, tornam-se relevantes nessa discussão, assim como à área da Ciência da Informação, e por isso não se findam, pois a todo momento a cada leitura e interpretação novas reflexões são propostas e com isso cada vez mais torna-se complexos as definições, e conceitos adotados.

Entendemos que a cultura é um fenômeno extremamente complexo assim como a informação. Desse modo não devemos nos conformar em deixar de lado discussões sobre cultura, práticas culturais, atividades culturais, dentro do campo da Ciência da Informação, pois ao refletir sobre o objeto da área, tais questões devem ser vistas como parte desta, na medida em que estas podem proporcionar transformações nos indivíduos.

Compreendemos que por meio da mediação cultural e da informação, não se pretende que os indivíduos/comunidades façam usos apenas da cultura e/ou da informação, mas sim que, possam por meio de elementos inseridos nesta, conheçam e se apropriem, alterem, transformem seus conhecimentos e por consequência o seu cotidiano. Parafraseando uma das ideias de Freire (1998), ensinar não é meramente transferir conhecimentos, assim também pensamos que ocorre com a mediação cultural e da informação. O intuito é criar condições, possibilidades para a construção de conhecimentos.

\section{Folguedos Alagoanos e a(s) mediação(ões)}

Os folguedos são manifestações tradicionais que podem ser visualisados por meio das danças, músicas, costumes e lendas apresentadas em determinadas comunidades. Os folguedos são parte de uma cultura e esta é parte constitutiva do cotidiano dos indivíduos, e por isso não deixa de atuar como um produto histórico da sociedade, pois consideramos que "[...] A cultura é uma manifestação da sociedade. Como tal, não existe cultura sem sociedade" (Lindoso, 2005, p. 31).

Diante dessa apresentação histórica e social sobre o fenômeno da cultura, sinalizando os folguedos enquanto elemento cultural representativo em Alagoas, apresentamos, por meio de dados da Secretaria de Estado e da Cultura em Alagoas, que o Estado possui uma diversificação em folguedos. Alguns estudiosos do folclore dizem que são quatorze folguedos natalinos, dois folguedos de festas religiosas, quatro folguedos carnavalescos com estrutura simples, dois torés e três danças, totalizando vinte e nove folguedos e danças características de Alagoas.

Entre os grupos de folguedos existentes no Estado temos os folguedos natalinos: Baianas, Guerreiro, Presépio, Maracatu, Baianas, Bumba-meu-boi, Pastoril, Fandango, Quilombo, Cavalhada, Marujada, Reisado, Chegança, Taieiras, Pastoril de Estudante. Nesse contexto verificou-se que a região do Nordeste possui uma diversidade de manifestações culturais, entre as quais podemos citar a literatura de cordel, a música, as emboladas e os repentes. Sobre isso (Dantas, 1986) enfatiza que a região ganha essa característica, em sua história, no que corresponde às atividades da monocultura da cana-de-açúcar, assim como a vida rural e o monopólio dos senhores de engenho. Vale destacar que os folguedos alagoanos são denominados neste trabalho como manifestações culturais advindas de um período de engenhos, em destaque do contexto político e econômico que 
marcou parte da história e cultura no Nordeste do Brasil.

Os folguedos, eram grupos festivos financiados pelos senhores de engenho, isto é, proprietários dos engenhos existentes na região. Eram homens respeitados e muito bem homenageados nas grandes festas populares que aconteciam dentro, e até mesmo, fora do Estado de Alagoas. Foram esses temidos senhores de engenho que financiavam muitos artistas entre repentistas e emboladores, violeiros, mestres, entre outros que deram início e disseminaram às atividades do folclore na região Nordeste do Brasil.

Atualmente, é possível verificar que os folguedos ao longo de todo o seu trajeto na cultura em Alagoas, ainda permanecem submissos, não mais diretamente sob as rédeas dos senhores de engenho, até porque essa posição foi alterada ao longo da história social, política e econômica do Estado. Um exemplo disso é relatado por Dantas (1986, p. 15), onde diz que a casa grande foi substituída por mansão urbana, assim como o senhor de engenho "esteriotipou-se" de usineiro. O momento é outro. Os folguedos encontram-se limitados a projetos culturais passageiros que ocorrem meramente por interesses políticos e econômicos locais. O mais inquietante desse jogo lúdico da realidade é que, ainda assim, os grupos de folguedos no Estado de Alagoas continuam a louvar e fazer honrarias aos senhores de engenho, coronéis, usineiros, hoje homens políticos, os quais ainda decidem sobre a cultura popular local. Diante disso podemos entender que os financiadores são os mesmos, só suas posições políticas tomaram outros rumos.

Os mestres de folguedos, como apresenta Dantas (1986, p. 11), faziam inúmeras louvações aos donos da casa grande e seus convidados. As cantorias eram comuns nos folguedos assim como ainda é, mas os elogios eram e ainda são para os "donos da casa", os "senhores de engenho", ou melhor os "usineiros", "senhores industriais", enquanto que o xingamento, também comum nas cantorias, se resumiam e ainda ocorre apenas direcionados aos "servos" os participantes, mestres, figurantes daquelas brincadeiras. Isso se justifica pelo fato de os senhores de engenho também compor as peças e após isso os mestres de folguedos ensaiavam com todo o grupo. Diégues Júnior (1980, p. 296), apresenta parte de um verso do folguedo denominado Reisado que segundo este mesmo autor diz ser uma dança iniciada em engenho, e ainda criada e promovida por negros e escravos:
Deus te salve casa-grande

$E$ a gente que nela mora

Venho dar as boas noites

Meus senhores e senhoras

Contudo, verificou-se que a estrutura patriarcal e agrária da época condicionava os mestres de folguedos e todo o grupo a uma situação de subserviência, mantendo-os por meio de relações servis. Esse quadro sofreu algumas alterações, porém os folguedos em Alagoaas ainda possuem laços de dependência, agora a projetos momentâneos, quando desses é ofertado algum financiamento para o custeio de festas populares promovidas na cidade. Para exemplificar esta condição basta a leitura de um verso registrado pelo folclorista Théo Brandão (1973, p. 62):

O Sinhô dono da casa

É quem pode vestí véu,

É quem se pode adorá

Abaixo de Deus do céu.

O sinhô dono da casa

Lá no céu tem um andô,

Para o sinhô se assentá

Quando deste mundo fô.

Diante disso, pensamos que os folguedos alagoanos, com toda a sua criatividade, elegância nas suas vestimentas e apresentações, da coragem e acima de tudo, vontade em tornar evidente suas atividades culturais, ainda não possuem autonomia para decidir sobre como, quando e o que deve ser feito para a cultura popular ser melhor reconhecida, respeitada e comunicada. Não que estes não desejem, mas acima deles estão outros que detém poder político e econômico. Em torno disso pensamos: e onde fica a mediação cultural? Suas propostas de aproximação entre indivíduos e as obras de cultura? E a apropriação?

Nesse relato sobre os folguedos observamos que a apropriação ocorre não por parte do público e sujeitos envolvidos com a cultura. A apropriação passa a ter um caráter negativo pelo modo como ocorre. Apropriam-se das artes, das suas linguagens, de um conjunto de elementos da cultura popular que poderiam estar sendo mediados considerando toda uma trajetória histórica, social e econômica, de luta e resistência dos grupos de folguedos em busca de espaço e acima de tudo respeito no âmbito da cultura popular local, pois consideramos que nesse contexto, a cultura é um elemento mediador, e por isso decisivo na configuração de um povo. Ela é mediadora entre a natureza e as ações humanas (Lindoso, 2005, p. 21).

De todo modo, ao entender que a cultura é ou deveria ser um elemento mediador, devemos 
considerar que nela há uma linguagem múltipla que necessita ser (re)vista e analisada, pois foi concebida e expressa por meio de um período de relações complexas em destaque da condição em que encontrava-se os sujeitos membros dos folguedos com os senhores de engenho, e por isso podemos dizer que a linguagem é também um elemento determinado nesse contexto.

No entanto, a linguagem é determinada pelo momento histórico, assim como, pelas contradições sociais, pelos conflitos ideológicos, tanto de classe, de gerações, de gênero como de grupos étnicos, entre outros. A linguagem é um produto inconsciente, semiconsciente dessas contradições. Logo, sua função comunicativa possui uma importante instância de integração e também ocultação frente as contradições sociais (Carboni e Maestri, 2003, p. 59-60).

Entende-se que a mediação cultural e da informação podem propor aos sujeitos uma relação dialógica e de autonomia, na medida em que se estende o espaço comunicacional entre os atores da cultura e a comunidade envolvida. Por isso, reconhecemos que o conhecimento desses processos, assim como sua aplicação, diante do contexto cultural no Estado de Alagoas, por exemplo, poderá proporcionar um olhar questionador sobre as condições em que se encontram os folguedos em Alagoas, no cenário da cultura popular local.

Espera-se com essas reflexões, ao menos provocar alguns questões que abarquem principalmente a ideia das mediações culturais e da informação para posteriores estudos que ressaltem a temática da cultura popular em Aagoas.

\section{Referências}

Aguiar, Vera Teixeira de (2004). O verbal e o não verbal. São Paulo: UNESP.

Almeida Júnior, O. F. de. (2009). Mediação da informação e múltiplas linguagens. // Tendências da Pesquisa Brasi- leira em Ciência da Informação. 2: 1 (jan.-dez.) http://inseer.ibict.br/ancib/index.php/tpbci/article/view/17/ 39 (2010-01).

Almeida Júnior, O. F. de (2009). La mediación de la información y la lectura informacional. // Ibersid. 3, 23-28. http://www.ibersid.org/ (2010-01-20).

Almeida Júnior, O. F. de (2007). Leitura, mediação e apropriação da informação. // Santos, Jussara Pereira dos. (Org.). A leitura como prática pedagógica na formação do profissional da informação. 1ed. Rio de Janeiro: Biblioteca Nacional, 2007. 1, 33-45.

Brandão, Théo. (1973). Folguedos natalinos. Maceió: Museu Theo Brandão.

Carboni, Florence; Maestri, Mário. (2003). A linguagem escravizada: língua, história e luta de classes. São Paulo: Expressão Popular.

Coelho Neto, J. T. (2012). Dicionário crítico de política cultural: cultura e imaginário. São Paulo; lluminuras.

Coelho Neto, J. T. (2011). Cultura e educação. São Paulo; Iluminuras: Itaú Cultural.

Dantas, Carmém Lúcia Tavares Almeida. (1986) Aspectos da cultura popular de Alagoas. Maceió: Museu Theo Brandão.

Davallon, J. ( 2007). A mediação: a comunicação em processo?. // Revista de Ciências da Informação e da Comunicação do CE-TAC. 11, 3-36. http://prisma.cetac.up .pt/edicao n4 junho de 2007/a mediacao a comunica cao_em_pr.html (2010-02).

Diégues Júnior, Manuel (1980). O bangüê nas alagoas: traços da influência do sistema econômico do engenho de açúcar na vida na vida e na cultura regional. Maceió: Edufal, 1980

Falcon, Francisco (2002). História Cultural: uma nova visão sobre a sociedade e a cultura. Rio de Janeiro: Campus.

Freire, Paulo (1998). Pedagogia da autonomia: saberes necessários à prática educativa. São Paulo: Paz e Terra, 1998.

Lindoso, Dirceu (2005). Interpretação da província: estudo da cultura alagoana. Maceió: EDUFAL, 2005. 131 p.

Machado, I. (2003). Escola de Semiótica: a experiência de Tártu - Moscou para o estudo da cultura. São Paulo: Ateliê Editorial, 2003. 189 p.

Ramonet, Ignácio (2003). O poder midiático. // Moraes, Denis de (org.). Por uma outra comunicação: mídia, mundialização cultural e poder. Rio de Janeiro: Record.

Enviado: 2014-04-01. Segunda versión: 2014-06-09. Aceptado: 2014-07-11. 
